\title{
HEMATOCELE GIGANTE SOBREINFECTADO IDIOPÁTICO
}

\author{
D. PASCUAL REGUEIRO, A. GARCÍA DE JALÓN MARTÍNEZ, M.A. TRÍVEZ BONED, \\ C. SANCHO SERRANO, S. GRACIA MONTOLIU, L.A. RIOJA SANZ
}

Servicio de Urología. Hospital Universitario Miguel Servet. Zaragoza.

Actas Urol Esp. 27 (8): 645-648, 2003

\section{RESUMEN}

\section{HEMATOCELE GIGANTE SOBREINFECTADO IDIOPÁTICO}

Varón de 45 años que es atendido por un marcado aumento de tamaño del hemiescroto izquierdo totalmente asintomático. El diagnóstico fue de hematocele aunque no se encontró causa evidente del sangrado.

Se llevó a cabo orquiectomía y exéresis completa de la túnica vaginal.

PALABRAS CLAVE: Hematocele.

\section{ABSTRACT}

INFECTED GIANT IDIOPATHIC HAEMATOCELE

A 45 year old male patient is attended for a marked increase in the size of the left hemiscrotum totally painless. The diagnosis was haematocele, but no cause was found for the bledding.

Orchidectomy and complete exeresis of the tunica vaginalis was carried out.

KEY WORDS: Haematocele.

$\mathrm{E}$ 1 hematocele es el acúmulo de sangre en la cavidad vaginal. Su origen puede estar en pequeños desgarros o perforaciones de la propia túnica vaginal, aunque normalmente traduce roturas en la albugínea testicular, única o múltiples siendo la causa casi siempre traumática.

Asímismo existen hematoceles secundarios por roturas de túnica vaginal en pacientes con tumores testiculares, hidroceles o trastornos de la coagulación.

Pueden presentarse de forma crónica ${ }^{1}$ siendo totalmente asintomáticos y sin evidenciarse una causa evidente de su origen.

Aquellos que alcanzan gran tamaño producen una compresión testicular que da origen a lesiones isquémicas y atrofias testiculares ${ }^{2}$.

Lo llamativo de este caso es la iconografía por el gran tamaño alcanzado por el escroto, así como la no identificación de una causa aparente del sangrado.

\section{CASO CLÍNICO}

Se trata de un varón de 45 años de edad que es atendido por nosotros en consultas en primera ocasión por la aparición repentina de un aumento llamativo de tamaño del hemiescroto izquierdo, totalmente indoloro. Interrogado el paciente, niega toda actividad física violenta, así como traumatismo accidental o provocado.

Desde el punto de vista urológico no presenta ningún tipo de antecedente.

A la exploración se evidencia un pene normal sin secreción uretral, un testículo derecho normal y un testículo izquierdo no palpable por la presencia de masa a tensión que es etiquetada de posible hidrocele, aunque la transiluminación no resulta del todo clara.

Se continúa el estudio con la realización de ecografría ${ }^{3}$ con los siguientes hallazgos: 
Masa escrotal con múltiples tabicaciones gruesas, y cavidades con masas flotando en su interior. Teste derecho normal e izquierdo desplazado y alargado.

En ese momento se plantea el diagnóstico diferencial entre hidrocele complicado o secundario a afectación testicular y hematocele.

El paciente es incluido en lista de espera para la realización de revisión quirúrgica escrotal, solicitando mientras la realización de un $\mathrm{TAC}^{3}$ con los siguientes hallazgos:

Colección intraescrotal voluminosa compatible con un hematoma tabicado que desplaza ampliamente el teste izquierdo.

Asímismo se solicitan marcadores tumorales testiculares para descartar un origen neoplásico resultando la BetaHCG y la alfa-fetoproteina normales.

Entre tanto, el paciente acude a urgencias por un cuadro febril de $40^{\circ} \mathrm{C}$ de siete días de evolución malestar general y aumento del tamaño escrotal que triplica el tamaño inicial y presentando signos inflamatorios en su superficie ${ }^{4}$.

El paciente presenta gran afectación del estado general y gran tamaño escrotal como puede evidenciarse en la Figura 1.

Se decide iniciar tratamiento antibioterápico i.v. con imipenen y antitérmicos realizándose de urgencias y bajo anestesia general drenaje quirúrgico de la colección a través de una escrototomía transversa ascendente siendo esta superior a 1500 cc de hematoma sobreinfectado con gran cantidad de coágulos.

En el acto quirúrgico se observa una intensa paquivaginalitis de $1.5 \mathrm{~cm}$ de grosor con coágulos organizados en su superficie, y un teste izquierdo desplazado, comprimido y rechazado con aspecto de rotura del mismo en su cara vaginal y siendo etiquetada la causa del sangrado la rotura de la albugínea testicular, como causa más frecuente del hamatocele (Fig. 2).
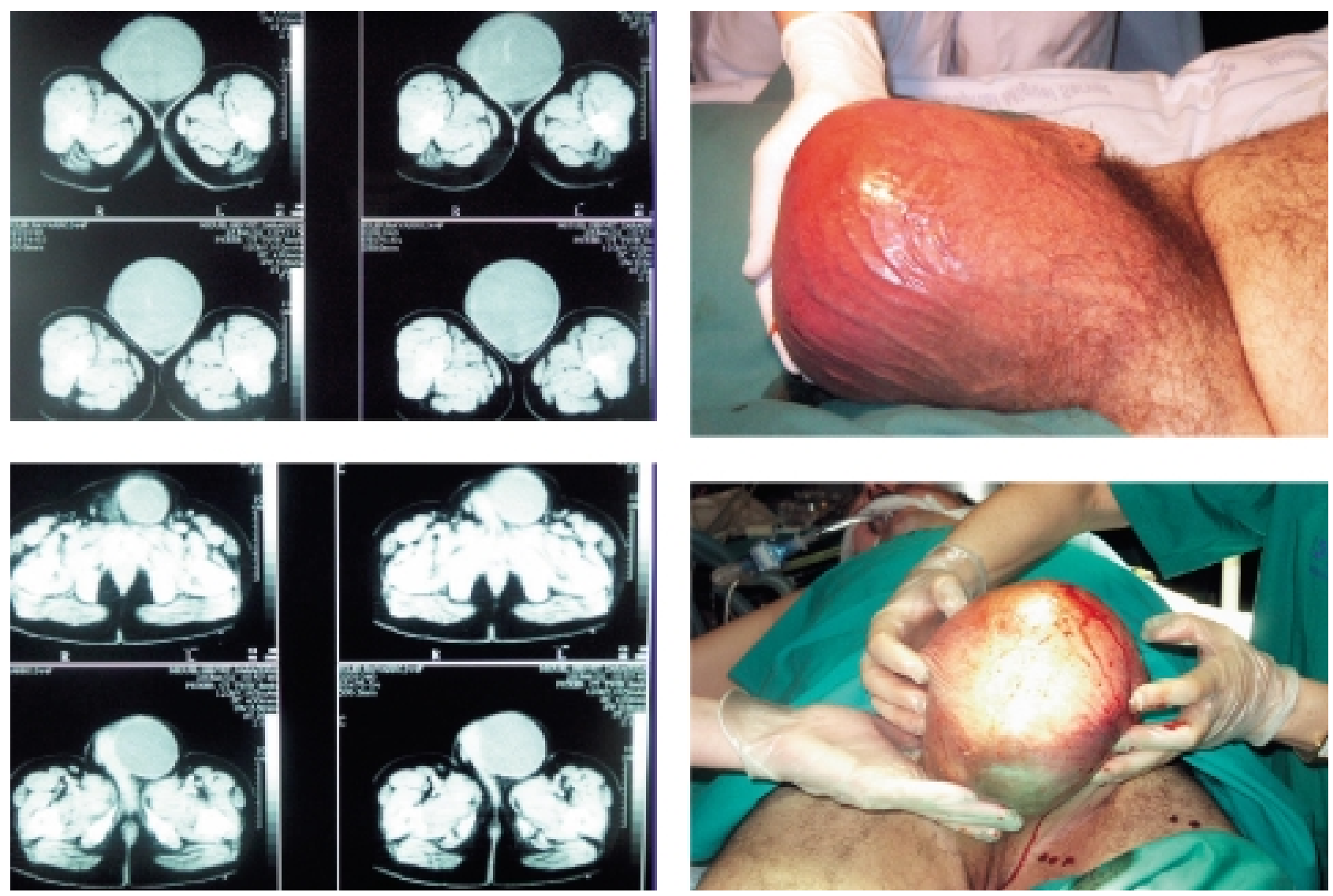

FIGURA 1. Hallazgos preoperatorios. A la derecha imágenes del TAC, donde se aprecia el gran tamaño de la colección intraescrotal izquierda que desplaza el pene y ambos testículos. A la izquierda exploración del paciente al ingreso y preparación preoperatoria. Llama la atención el gran tamaño del hemiescroto izquierdo. 

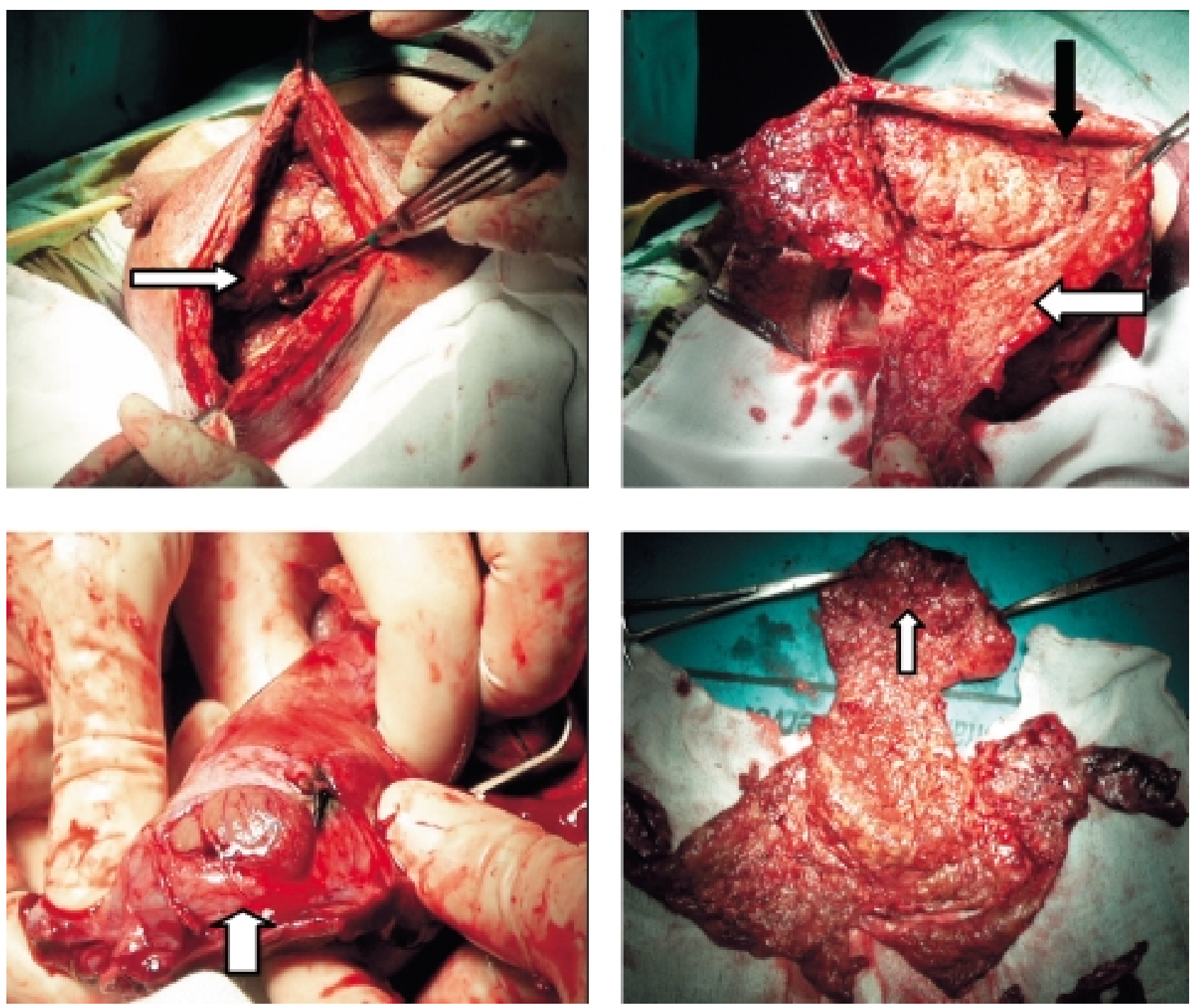

FIGURA 2. Cirugía y pieza quirúrgica. De izquierda a derecha y de arriba abajo:

Incisión quirúrgica, cavidad drenada señalada por la flecha blanca. Se aprecia el gran engrosamiento de la vaginal testicular. Flecha blanca señalando la vaginal prácticamente liberada del resto de capas testiculares.

Flecha negra señalando la posición del testículo izquierdo. Identificación de la cara externa testicular, flecha blanca. Pieza de resección: vaginal engrosada resecada en su totalidad.La flecha blanca señala la cara interna del testiculo.

Se decide realizar orquiectomía y exéresis completa de la vaginal, lo que resulta laborioso por la intensa reacción inflamatorio-fibrótica.

Al final de la intervención se dejan dos drenajes de Penrose en la cavidad, y se cierra la incisión en dos planos.

La evolución del paciente es sorprendentemente favorable encontrándose afebril a partir del día siguiente el drenaje.

Asímismo no presenta apenas débito por los drenajes y con un muy buen aspecto de la herida quirúrgica, pudiendo ser dado de alta al tercer día.
El estudio anatomopatológico de la pieza quirúrgica demostró una absoluta integridad de la albugínea testicular no hallándose una causa evidente del sangrado ${ }^{5}$.

\section{COMENTARIO}

Nos encontramos ante un caso de hematocele crónico de grandes dimensiones que provoca un cuadro florido de reagudización como consecuencia de la sobreinfección del contenido hemático.

Asímismo no se pudieron identificar las causas que motivaron el sangrado, el paciente no 
presentaba trastornos de la coagulación, y negó en todo momento un origen traumático.

Es lógico pensar que el origen haya sido la rotura de algún vaso de la túnica albugínea aunque no se pudieron determinar las causas ${ }^{5}$.

También resulta lícito pensar que en caso de que no se hubiera producido la reagudización, el hematocele hubiera permanecido totalmente asintomático a lo largo del tiempo.

Lo que sí es evidente es que la compresión testicular motivada por el acúmulo de sangre a tensión, había producido un desplazamiento, aplanamiento e isquemia testicular con disminución aparente de su tamaño.

\section{REFERENCIAS}

1. MORIYAMA M, YOKOI K, TSUGAWA R, NOJIMA T.: A case of chronic scrotal hamatocele. Hinyokika Kiyo 1996 jul; 42 (7): 543-545.
2. GOHJI K, HASUNUMA Y, TAKAGI S, ARQAKAWA S, MATSUMOTO O, KAMIDONO S.: A case on chronic scrotal hematocele and review of the literature. Hinyokika Kiyo 1992 dec; 38 (12): 14131415.

3. HADDAD FS, MANNE RK, NATHAN MH.: The pathological, ultrasonographic and computerized tomografhic characteristics of chronic hematocele. $J$ Urol 1988 mar; 139 (3): 594-595.

4. LEIBIVITCH I, RAMON J, BEN CHAIM J, NASS D, GOLDWASSER B.: Chronic hematocele complicatiing renal failure and hemodialysis. J Urol 1991 jul; 146 (1): 162-164.

5. PEYRI REY E.: Hematocele de la túnica vaginal. Actas Urol Esp 1990 jul-aug; 14 (4): 279-281.

Dr. D. Pascual Regueiro

Avda. Compromiso de Caspe, 27-29, $2^{\circ}$ A

50002 Zaragoza

(Trabajo recibido el 15 octubre de 2002) 